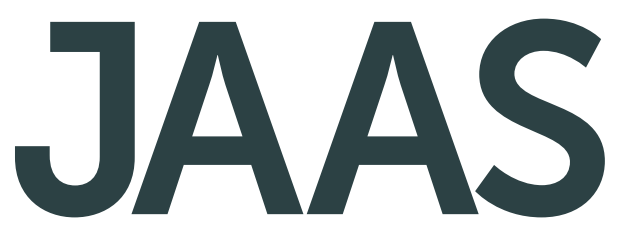

Journal of Analytical Atomic Spectrometry www.rsc.org/jaas

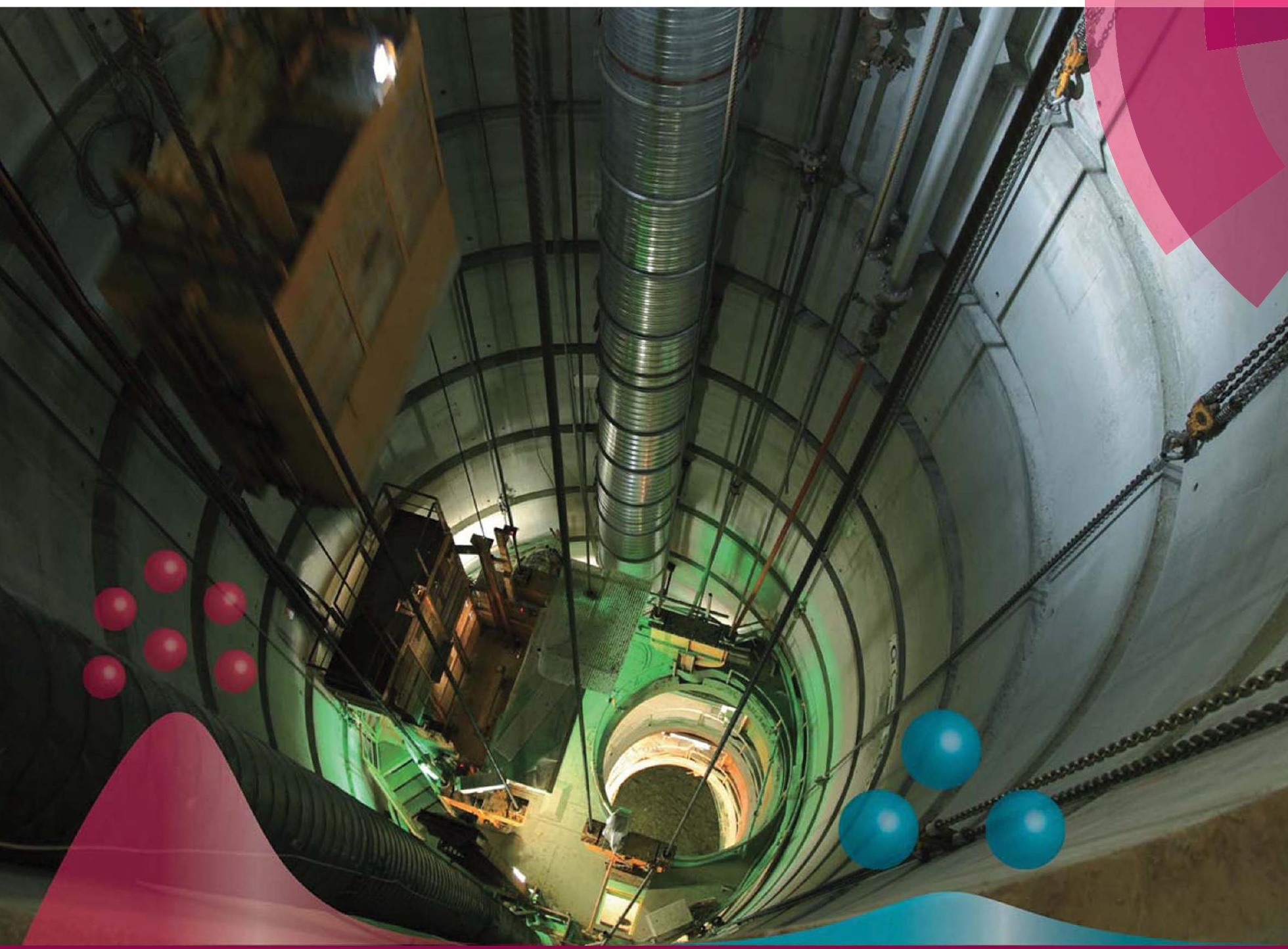

Themed issue: Analysis of nanomaterials by field flow fractionation and single particle ICP-MS

ISSN 0267-9477

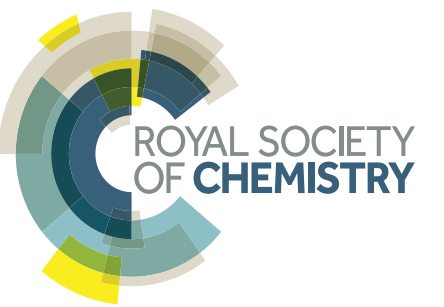




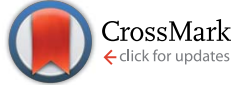

Cite this: J. Anal. At. Spectrom., 2015, 30, 1229

Received 16th March 2015 Accepted 13th May 2015

DOI: $10.1039 / \mathrm{c5ja00088b}$

www.rsc.org/jaas

\section{Comparative study of granitic and sedimentary groundwater colloids by flow-field flow fractionation coupled with ICP-MS}

\begin{abstract}
T. Saito, ${ }^{\star a}$ T. Hamamoto, ${ }^{\mathrm{b}}$ T. Mizuno, ${ }^{\mathrm{c}}$ T. Iwatsuki ${ }^{\mathrm{d}}$ and S. Tanaka ${ }^{\mathrm{b}}$
Colloids in deep underground water play an important role in the migration of radionuclides and are of great concern in the safety assessment of the geological disposal of nuclear wastes. Size distribution and elemental compositions of colloids in granitic and sedimentary deep groundwater were determined by flow-field flow fractionation (Fl-FFF) combined with inductively coupled plasma mass spectrometry (ICP-MS). Great care was taken to examine colloids over a wide range of size and to detect trace elements associated with them. In the granitic groundwater organic colloids and various inorganic elements were found in limited size ranges. The presence of different types of organic colloids was suggested in this groundwater. Most of the inorganic elements exhibited similar size distributions at $<10$ $\mathrm{nm}$, which largely overlapped with organic colloids rich in fluorophores. In the sedimentary groundwater small organic and probably inorganic colloids were found at $<5 \mathrm{~nm}$ together with larger inorganic colloids. Organic colloids in this groundwater were homogeneous in terms of their sizes and the compositions of chromophores and fluorophores. The size distribution of inorganic elements at $<10 \mathrm{~nm}$ depended on their types, indicating the presence of different host colloidal phases.
\end{abstract}

\section{Introduction}

Natural colloids are inorganic particles, organic macromolecules, or their composites, having sizes ranging from $1 \mathrm{~nm}$ to 1 $\mu \mathrm{m}$; they can be found in various environments including soils, rivers, the ocean, and groundwater. ${ }^{1}$ Examples of inorganic colloids are clay minerals and iron (oxy)hydroxides, both of which result from chemical weathering of host rocks; ${ }^{2}$ those of organic colloids are humic substances, which are refractory organic materials resulting from decomposition and condensation of the remains of plants, animals, and microorganisms. ${ }^{3}$ Natural colloids readily interact with various pollutants and modify their reactivity, bio-availability, and toxicity. Organic pollutants can be captured by hydrophobic moieties of humic substances; ${ }^{4}$ metal ions such as trace metals and radionuclides can bind to functional groups on the surfaces of mineral colloids or to those inside the structures of organic colloids., ${ }^{3,5,6}$ As the transport behaviors of colloids in the environment are

${ }^{a}$ Advanced Science Research Center, Japan Atomic Energy Agency, 2-4 Shirakata Shirane, Tokai-mura, Ibaraki 319-1195, Japan. E-mail: saito.takumi@jaea.go.jp

${ }^{b}$ Department of Nuclear Engineering and Management, School of Engineering, The University of Tokyo, 7-3-1 Hongo, Bunkyo-ku, Tokyo 113-8656, Japan

${ }^{c}$ Horonobe Underground Research Center, Japan Atomic Energy Agency, 432-2 Hokushin, Horonobe-cho, Hokkaido 098-3224, Japan

${ }^{d}$ Mizunami Underground Research Laboratory, Japan Atomic Energy Agency, 1-64, Yamanouchi, Akeyo-cho, Mizunami-shi, Gifu 509-6132, Japan

$\dagger$ Former professor of the Department of Nuclear Engineering and Management, School of Engineering, The University of Tokyo. rather different from those of small contaminant molecules, due to the differences in their sizes and charge densities, their binding to natural colloids can significantly alter the mobility of contaminants. $^{7}$ In some cases natural colloids can facilitate their transport. ${ }^{7-10}$ This is of great concern for geological disposal of nuclear waste, ${ }^{\mathbf{1 1}}$ as the safety of the disposal must be assessed by considering the migration of radionuclides released from a deep underground repository.

The nature and amount of colloids in deep groundwater has been an active topic of research for decades. ${ }^{\mathbf{1 2 - 1 5}}$ Vilks et al. ${ }^{\mathbf{1 2}}$ reported the existence, concentration, and size distribution of groundwater colloids in different geological settings in Canada, using ultrafiltration. Those authors also evaluated the retention of naturally occurring radionuclides such as radium ( $\mathrm{Ra})$, thorium (Th), and uranium (U) in groundwater colloids. Degueldre, et al. ${ }^{\mathbf{1 3}}$ characterized colloids sampled in granitic groundwater and studied their stability and mobility. Criteria for colloid-facilitated transport of contaminants have been proposed, based on reviews of relevant field studies and laboratory experiments. ${ }^{14}$

One of the difficulties encountered in the analysis of natural colloids is the heterogeneity both in their size and composition. Colloids found in natural water samples tend to exist over a wide range of sizes and consist of different types of materials associating with each other. ${ }^{16,17}$ Conventional (ultra)filtration techniques only provide discrete information and may not fully resolve such heterogeneity. This is also the case for groundwater colloids. Only recently has detailed size distribution and 
composition of natural colloids become available with emergence of continuous size fractionation techniques such as flowfield flow fractionation (Fl-FFF), ${ }^{18-21}$ size exclusion chromatography (SEC), ${ }^{22,23}$ and capillary electrophoresis. ${ }^{24,25}$ These techniques can easily be combined with different types of detection methods to probe various properties of colloids. ${ }^{20-23}$

In Fl-FFF colloids are forced to accumulate near a so-called accumulation wall that is made of a membrane largely permeable for solute and solvent molecules by a force field created by cross flow. ${ }^{26}$ Smaller colloids tend to be distributed far away from the wall due to their large thermal mobility and are transported faster than larger ones by parabolic laminar tip flow. Fl-FFF has certain advantages over the other techniques: the range and resolution of fractionation can be easily adjusted by changing flow parameters; in theory the retention time of a given colloidal particle, which is the time necessary for the particle to travel through the channel of the Fl-FFF and reach a detector, mathematically relates to its diffusion coefficient and thus to its hydrodynamic diameter $\left(d_{\mathrm{H}}\right)$. This technique has been widely applied for environmental colloids in surface water and shallow groundwater, ${ }^{\mathbf{1 8 , 2 0 , 2 1}}$ but has not been applied for those in deep groundwater mostly due to the relatively low concentrations of colloids in deep groundwater and the difficulty in obtaining deep groundwater samples. ${ }^{\mathbf{1 9}}$

The objective of this study is to compare the size distribution and elemental compositions of colloids in granitic and sedimentary deep groundwater by Fl-FFF combined with ICP-MS (inductively coupled plasma mass spectrometry). In our previous study colloids in a limited range of size of the granitic groundwater were examined. ${ }^{19}$ We have extended it by using the gradient cross flow technique ${ }^{27,28}$ and measuring even larger colloids appearing in the washing step to determine the similarities and differences in the size distribution and compositions of colloids in both the groundwater samples over a wide size range. The comparison of these groundwater samples is of great importance, as their geological settings are potential candidates of repository sites in geological disposal programs of many countries. The Japan Atomic Energy Agency operates two underground research laboratories (URLs) for general feasibility studies of high-level nuclear waste disposal in Japan. ${ }^{29,30}$ Groundwater samples obtained in these URLs were used in this study, so that alternation of colloids due to sampling was minimized. Fractionated groundwater colloids by Fl-FFF were subsequently analyzed by on-line UV/Vis and fluorescence detectors for organic colloids and ICP-MS for quantification of inorganic constituents, which are either major colloid-building components or minor components binding to them.

\section{Experimental}

\subsection{Groundwater sampling}

The groundwater was sampled in glass vials with Teflon ${ }^{\circledR}$ coating and airtight rubber septums (USL vials, UNIVERSAL Co., Ltd), which were washed once with $5 \mathrm{wt} \%$ pure nitric acid (Ultrapur, Kanto Chemical) and several times with pure water. They were filled with Ar gas before groundwater sampling. Collected groundwater samples were transported to a surface laboratory, and stored at $4{ }^{\circ} \mathrm{C}$ before pre-treatment. Granitic groundwater was obtained on August 20th, 2013 from a borehole (09MI21) at a depth of $-300 \mathrm{~m}$ in the Mizunami URL located in Gifu Prefecture, Japan. The geology of the sampling location is the late Cretaceous Toki granite formation unconformably overlain by the Pliocene to Pleistocene Seto Group and the Miocene sedimentary Mizunami Group. ${ }^{30}$ Sedimentary groundwater was obtained on December 2nd, 2013 from a borehole (09-V250-M02) at a depth of $-250 \mathrm{~m}$ in the Horonobe URL located in Hokkaido Prefecture, Japan. The sampling location is at the boundary of the Pleiocene Koetoi and the Miocene Wakkanai formations, which are composed of diatomaceous and siliceous mudstones, respectively. The detailed geology and geochemistry of the URLs are described elsewhere. ${ }^{29,30}$ Basic physicochemical parameters and the concentrations of the major components of the groundwater are periodically measured by JAEA and the data taken on the days closest to the sampling dates are summarized in Table 1 . These boreholes are separated into several sections by impermeable packers, and the results of the groundwater samples obtained from the second sections are presented for both the URLs.

\subsection{Pretreatment of the groundwater samples}

The groundwater samples were transferred to an Ar filled glove box and filtered through a $0.45 \mu \mathrm{m}$ polyethersulfone (PES) membrane (Nalgene, Thermo Fisher Scientific) to remove large particulate materials that may interfere with the fractionation of smaller particles. ${ }^{31}$ One of the difficulties in groundwater colloidal analyses, compared with those of surface water colloids, is the relatively low concentration of colloids. To mitigate this, the filtered groundwater samples were concentrated with a stirred cell (Millipore) equipped with a $1 \mathrm{kDa}$ regenerated cellulose membrane (YM-1, Millipore). The apparatus used for these pre-treatments were preliminarily washed by a $5 \mathrm{mmol} \mathrm{L}{ }^{-1}$ solution of ethylenediaminetetraacetate disodium salt (EDTA-2Na, Wako Pure Chemicals) and pure water. The concentration factors determined from the weights of the original samples and the retentates were 8.0 and 9.6 for the granitic and sedimentary groundwater, respectively.

\subsection{Fl-FFF-ICP-MS measurements}

The Fl-FFF system used in this study is similar to the one reported elsewhere ${ }^{\mathbf{1 9}}$ and briefly described here. Size fractionation of the concentrated groundwater was performed with an asymmetrical trapezoidal Fl-FFF system (AF2000 FOCUS, Postnova Analytics) equipped with a 300 Da PES membrane and a $1.1 \mathrm{~mL}$ injection loop. The effluent was a $5 \mathrm{mmol} \mathrm{L}^{-1} \mathrm{NaCl}$ solution.

Size fractionation by Fl-FFF consists of the three steps. In the focusing step, colloids introduced into the channel are forced into a narrow band using the opposing tip and focusing flows. In the subsequent elution step, the focus flow is turned off and colloids are transported by the tip flow under the force field created by the cross flow with a flow rate of $V_{\mathrm{c}}$. In the final washing step colloids still retained in the channel are washed out by the tip flow with $V_{\mathrm{c}}=0$. With a constant $V_{\mathrm{c}}$ in the elution 
Table 1 Basic physicochemical parameters of the granitic and sedimentary groundwater

\begin{tabular}{|c|c|c|c|c|c|c|c|c|c|c|}
\hline & $\mathrm{pH}$ & $\begin{array}{l}\mathrm{EC}^{c} \\
\left(\mathrm{mS} \mathrm{m}^{-1}\right)\end{array}$ & $\begin{array}{l}\mathrm{Eh}^{d} \\
(\mathrm{mV})\end{array}$ & $\begin{array}{l}\operatorname{TOC}^{e} \\
\left(\mathrm{mg} \mathrm{L}^{-1}\right)\end{array}$ & $\begin{array}{l}\operatorname{TIC}^{f} \\
\left(\mathrm{mg} \mathrm{L}^{-1}\right)\end{array}$ & $\begin{array}{l}\mathrm{Na}^{+} \\
\left(\mathrm{mg} \mathrm{L}^{-1}\right)\end{array}$ & $\begin{array}{l}\mathrm{K}^{+} \\
\left(\mathrm{mg} \mathrm{L}^{-1}\right)\end{array}$ & $\begin{array}{l}\mathrm{F}^{-} \\
\left(\mathrm{mg} \mathrm{L}^{-1}\right)\end{array}$ & $\begin{array}{l}\mathrm{Cl}^{-} \\
\left(\mathrm{mg} \mathrm{L}^{-1}\right)\end{array}$ & $\begin{array}{l}\mathrm{Br}^{-} \\
\left(\mathrm{mg} \mathrm{L}^{-1}\right)\end{array}$ \\
\hline Mizunami, granitic $^{a}$ & 9.8 & 77 & 44 & $<0.5$ & 5.2 & 122 & 0.4 & 9.2 & 200 & 0.4 \\
\hline
\end{tabular}

${ }^{a}$ Measured on September 24th, 2013. ${ }^{b}$ Measured on December 16th, 2013. ${ }^{c}$ Electronic conductivity. ${ }^{d}$ Redox potential against standard hydrogen electrode (SHE). The Eh of the sedimentary groundwater was not measured. ${ }^{e}$ Total organic carbon. ${ }^{f}$ Total inorganic carbon.

step one can evaluate the hydrodynamic diameter of a colloid, $d_{\mathrm{H}}$, from the retention ratio, $R$, defined as a ratio of the retention time $\left(t_{\mathrm{r}}\right)$ to the void time $\left(t_{0}\right)$, which is the elution time of a nonretained component such as sodium azide. ${ }^{26,31}$

In this study we adapted the gradient cross flow method, ${ }^{27,28}$ where $V_{\mathrm{c}}$ is decreased over time in order to extend the fractionation range in a given experimental time without a large loss of resolution for relatively smaller sizes. $V_{\mathrm{c}}$ was quadratically decreased as a function of time, $t$, in the form $V_{\mathrm{c}}=0.9(t-30)^{2} / 900$ for the granitic groundwater, and $V_{\mathrm{c}}=1.5(t-30)^{2} / 900$ for the sedimentary groundwater. For this method the theoretical relationship between $d_{\mathrm{H}}$ and $R$ is no longer valid; instead a linear relationship with an intercept of zero between $t_{\mathrm{r}}$ and $d_{\mathrm{H}}$ of the vitamin and protein standards under the same measurement conditions as those employed for the analyses of the deep groundwater samples was used to estimate $d_{\mathrm{H}}$ of colloids in the groundwater samples from the obtained $t_{\mathrm{r}}$. The biomolecular standards used in this study are vitamin $\mathrm{B} 12\left(d_{\mathrm{H}}=1.7 \mathrm{~nm}\right)$, bovine erythrocyte carbonic anhydrase $\left(d_{\mathrm{H}}=4.8 \mathrm{~nm}\right)$, bovine serum albumin $\left(d_{\mathrm{H}}=7.9 \mathrm{~nm}\right)$, sweet potato $\beta$-amylase $\left(d_{\mathrm{H}}=11.1\right.$ $\mathrm{nm})$, and bovine thyroglobulin $\left(d_{\mathrm{H}}=18.7 \mathrm{~nm}\right) .^{32,33}$ They were purchased from Aldrich and used without further purification. The results of the size calibration of the Fl-FFF system are shown in Fig. 1. The parameters used in the analyses of the granitic and sedimentary groundwater samples are tabulated in Table 2 . If we extrapolate the ranges of the size calibration, the ends of the

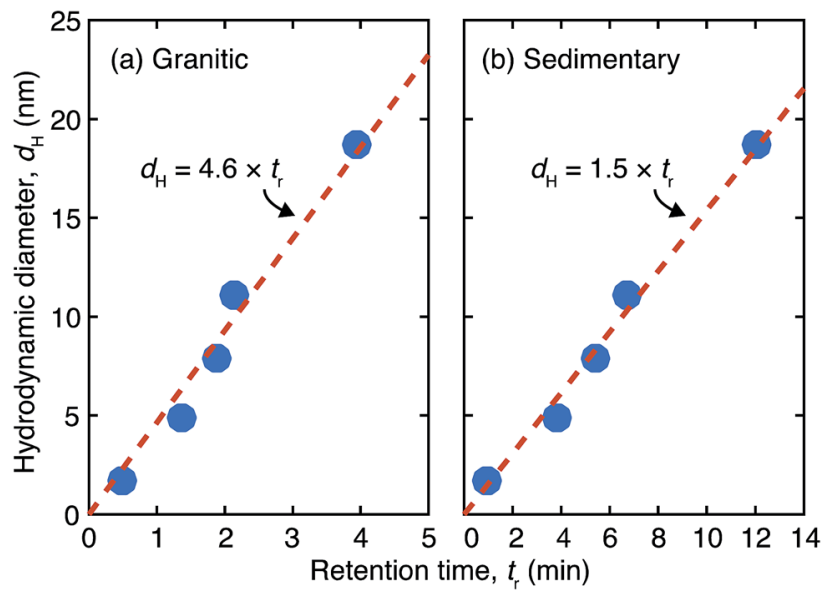

Fig. 1 Size calibration results of the Fl-FFF equipment with the protein and vitamin standards under gradient cross flow for (a) the granitic and (b) sedimentary groundwater samples. elution step correspond to $138 \mathrm{~nm}$ for the granitic groundwater and $46 \mathrm{~nm}$ for the sedimentary groundwater. Furthermore, elution of colloids in the washing step was also measured to examine the presence of even larger colloids.

The effluent from the Fl-FFF was first measured by a UV/Vis detector (SPD-20A, Shimadzu) at $255 \mathrm{~nm}$ and then by a fluorescence detector (RF-10AXL, Shimadzu) at the excitation wavelength of $255 \mathrm{~nm}$ and the emission wavelength of $475 \mathrm{~nm}$ for organic colloids. After the fluorescence detector, the effluent containing size-fractionated colloids were acidified with $5 \mathrm{wt} \%$ pure nitric acid, which was introduced at a flow rate of $1.0 \mathrm{~mL}$ $\min ^{-1}$ using an isocratic pump (GL Sciences, PU 714). The acidification was meant to extract target metal ions from colloids and maximize their detection by ICP-MS. The acidified effluent was transported to an ICP-MS (Agilent $7500 \mathrm{cx}$ ) after reducing the flow rate to $0.3 \mathrm{~mL} \mathrm{~min}^{-1}$ using a micro splitter valve (GL science) and mixed with a small amount of a $500 \mathrm{ppb}$ In solution as an internal standard. No collision gas was used for the measurements. A switching valve was inserted after the outlet of the Fl-FFF to introduce external standard solutions for lanthanide elements (AG-MECAL1-ASL-1, AccuTrace) and remaining elements (XSTC-622, SPEX) to calibrate the ICP-MS. The same switching valve was used to directly introduce the groundwater samples to the detectors without fractionation for the determination of the recovery rates of organic colloids and inorganic elements.

Table 2 Operational parameters of the Fl-FFF analyses ${ }^{a}$

\begin{tabular}{|c|c|c|c|c|}
\hline & \multicolumn{2}{|c|}{$0.26(0.44)$} \\
\hline & \multicolumn{4}{|c|}{ Duration of the steps (min) } \\
\hline Focusing step & & & \multicolumn{2}{|c|}{20} \\
\hline Elution step & & & \multicolumn{2}{|c|}{30} \\
\hline Washing step & & & \multicolumn{2}{|c|}{$60(30)$} \\
\hline & $V_{\mathrm{t}}$ & $V_{\mathrm{f}}$ & $V_{\mathrm{c}}$ & $V_{\text {out }}$ \\
\hline \multicolumn{5}{|c|}{ Flow parameters ${ }^{b}\left(\mathrm{~mL} \min ^{-1}\right)$} \\
\hline Focusing step & $0.1(0.2)$ & $1.8(2.3)$ & $0.9(1.5)$ & 1.0 \\
\hline Elution step & $\begin{array}{l}1.9 / 1.0 \\
(2.5 / 1.0)\end{array}$ & $\begin{array}{l}0 \\
0\end{array}$ & $\begin{array}{l}0.9 / 0 \\
(1.5 / 0)\end{array}$ & 1.0 \\
\hline Washing step & 1.0 & 0 & 0 & 1.0 \\
\hline
\end{tabular}

${ }^{a}$ Numbers in parentheses are those used in the analyses of the sedimentary groundwater. ${ }^{b}$ Flow rates of the tip $\left(V_{\mathrm{t}}\right)$, focus $\left(V_{\mathrm{f}}\right)$, cross $\left(V_{\mathrm{c}}\right)$, and detector $\left(V_{\text {out }}\right)$ flows. In the elution step $V_{\mathrm{c}}$ and $V_{\mathrm{t}}$ was quadratically decreased from the initial to final values (the numbers separated by slashes), while keeping $V_{\text {out }}$ constant, i.e. $V_{\text {out }}=V_{\mathrm{t}}-V_{\mathrm{c}}$. 
The results of the ten representative elements are presented below. The measured isotopes for these elements were ${ }^{27} \mathrm{Al},{ }^{43} \mathrm{Ca}$, ${ }^{55} \mathrm{Mn},{ }^{56} \mathrm{Fe},{ }^{65} \mathrm{Cu},{ }^{88} \mathrm{Sr},{ }^{95} \mathrm{Mo},{ }^{139} \mathrm{La},{ }^{182} \mathrm{~W}$, and ${ }^{238} \mathrm{U}$. For the granitic groundwater the peak concentrations of the isotopes were larger than the quantification limits (QLS), which are defined as $10 \sigma$ of the corresponding background levels, except for ${ }^{56} \mathrm{Fe}$ and ${ }^{238} \mathrm{U}$, where $\sigma$ stands for the standard deviation. For the sedimentary groundwater that of ${ }^{95} \mathrm{Mo}$ was below the QL and close to the detection limit (DL), which is defined as $3 \sigma$ of the corresponding background levels; that of ${ }^{238} \mathrm{U}$ was close to the QL (93\% of the QL).

\section{Results and discussion}

\subsection{Fl-FFF size distribution and composition of colloids in the granitic groundwater}

Size distribution, which is known as the fractogram in Fl-FFF, of the organic colloids and the inorganic elements are presented in Fig. 2 as a function of $t_{\mathrm{r}}$. Note that the ranges of $t_{\mathrm{r}}$, for which the size calibration with the vitamin and protein standards was performed $\left(d_{\mathrm{H}} \leq 18.7 \mathrm{~nm}\right)$, are specified in the fractograms. In these plots the fractograms in the washing step are also shown, which conceivably reflect the size distributions of the colloids beyond the elution step, as smaller colloids located close to the outlet of the channel tend to elute first. The recovery rates of the organic colloids detected by the UV/Vis absorbance and the fluorescence emission, as well as the inorganic elements by ICPMS, are tabulated in Table 3. These values likely depend on the underlying sizes of colloids, as relatively small colloids and associated trace elements may be discharged through the accumulation wall in the focusing step. In particular the recovery rate for the organic colloids calculated from the UV/Vis fractogram is smaller than that from the fluorescence fractogram, reflecting a smaller size range of the former, as discussed below. Mo and $\mathrm{W}$ exhibited a markedly small recovery, which
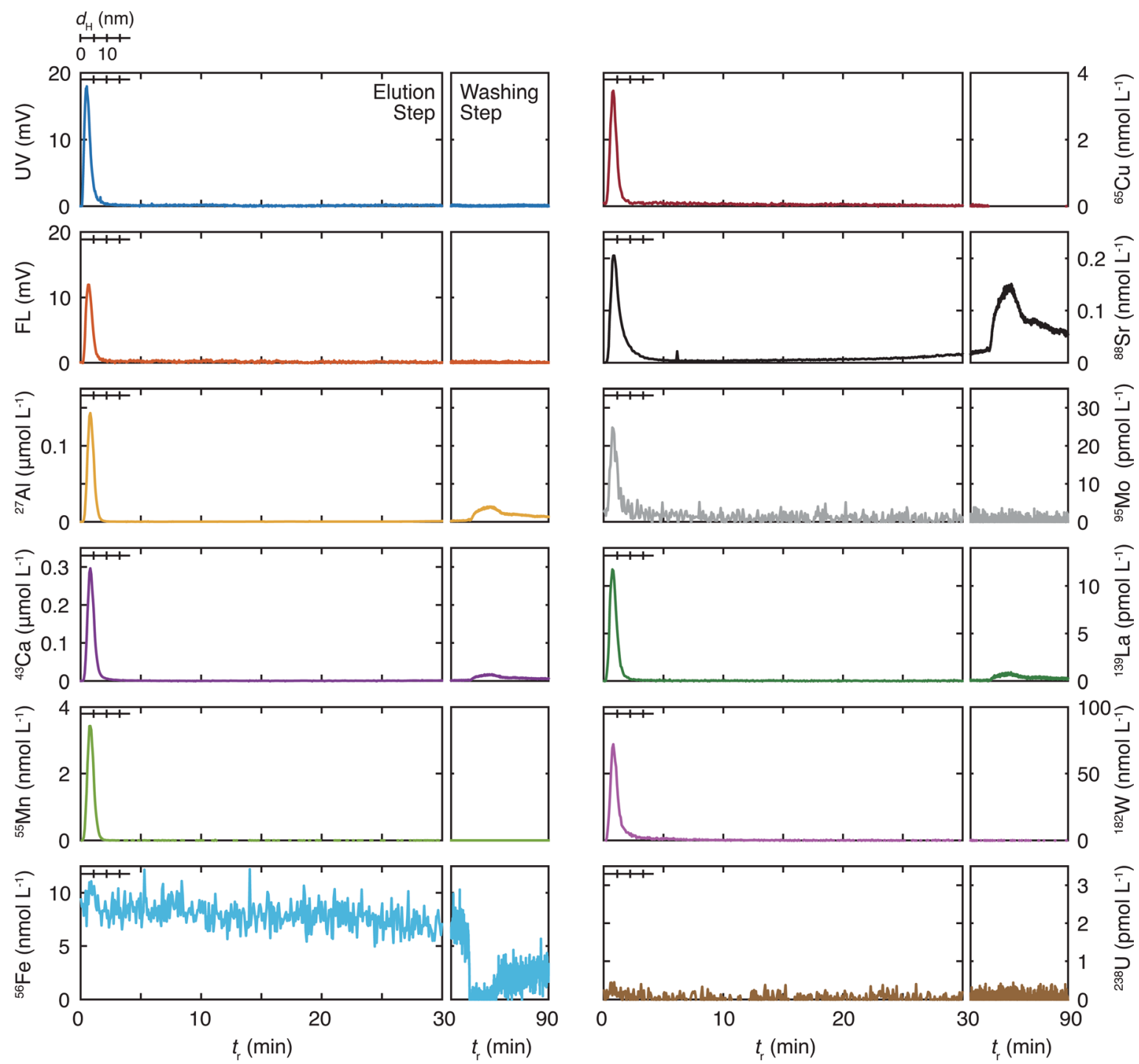

Fig. 2 Fl-FFF fractograms of the organic colloids and the inorganic elements in the granitic groundwater as a function of the retention time $\left(t_{r}\right)$. The range of $t_{r}$, which was calibrated for the hydrodynamic diameter $\left(0 \leq d_{H} \leq 18.7 \mathrm{~nm}\right)$, is given in each fractogram. The organic colloids were measured by the UV/Vis (UV) and fluorescence (FL) detectors. The elution profiles in the washing step are also presented as a function of $t_{\mathrm{r}}$. 
Table 3 Recovery rates (\%) of the measured isotopes for the Fl-FFFICP-MS analyses of the granitic and sedimentary groundwater samples

\begin{tabular}{|c|c|c|}
\hline & Granitic & Sedimentary \\
\hline \multicolumn{3}{|c|}{ Organic colloids } \\
\hline UV/Vis & 10.1 & 109.9 \\
\hline Fluorescence & 26.0 & 101.1 \\
\hline \multicolumn{3}{|c|}{ Inorganic elements } \\
\hline${ }^{27} \mathrm{Al}$ & 48.1 & 154.7 \\
\hline${ }^{43} \mathrm{Ca}$ & 19.7 & 1.9 \\
\hline${ }^{55} \mathrm{Mn}$ & 20.3 & 16.7 \\
\hline${ }^{56} \mathrm{Fe}$ & $-^{a}$ & 52.2 \\
\hline${ }^{65} \mathrm{Cu}$ & 30.7 & 21.4 \\
\hline${ }^{88} \mathrm{Sr}$ & 14.1 & 0.3 \\
\hline${ }^{95} \mathrm{Mo}$ & 0.8 & 42.1 \\
\hline${ }^{138} \mathrm{La}$ & 294.4 & 389.7 \\
\hline${ }^{182} \mathrm{~W}$ & 4.0 & 32.2 \\
\hline${ }^{238} \mathrm{U}$ & $-^{a}$ & 10.6 \\
\hline
\end{tabular}

may indicate similar chemical forms of these elements, most likely in the form of polyanions. For La contamination was suspected. As shown in Fig. 2 and Table 3, Fe and U were not detected in this study, which contradicts the previous one. ${ }^{19}$ For $\mathrm{U}$ this may suggest the possibility of a temporal variation of the total concentrations or size distributions. The use of a high resolution ICP-MS would be necessary to reveal the association of $U$ with colloids in this groundwater. Reduction of the interferences by polyatomic ions and the relatively large background signals may improve the situation for Fe and also some other elements such as Al.

The inorganic elements other than $\mathrm{Fe}$ and $\mathrm{U}$ are found in the size range less than $10 \mathrm{~nm}$ and their distributions are largely overlapped with those of the organic colloids detected by UV absorption and fluorescence emission. These trends are consistent with the results of the previous Fl-FFF study ${ }^{19}$ and suggest a possible role for organic colloids as hosts for these inorganic elements, although the presence of inorganic colloids constituting the elements with relatively large concentrations such as $\mathrm{Al}$ and $\mathrm{Ca}$ and incorporation of the trace elements is likely as well. Some elements such as $\mathrm{Al}, \mathrm{Ca}, \mathrm{Sr}$, and La exhibit additional peaks in the washing step at $t_{\mathrm{r}} \sim 76 \mathrm{~min}$, where no organic colloids exist, according to the UV and fluorescence fractograms. This suggests the presence of relatively large inorganic colloids. In the previous study both $\mathrm{Sr}$ and Ca showed similar fractograms with broad peaks around $20 \mathrm{~nm},{ }^{19}$ which are not seen in the present study. Although the peak locations are different, similar behaviors of these elements observed in this and the previous studies strongly suggest the presence of common underlying processes governing them.

One of the most important findings in the Fl-FFF analysis of the granitic groundwater, compared with the previous study, ${ }^{19}$ is the absence of colloids in an intermediate size range at $d_{\mathrm{H}}>$ $18.7 \mathrm{~nm}$ and $t_{\mathrm{r}}<30 \mathrm{~min}$. The latter corresponds to about 140 $\mathrm{nm}$, if the range of the size calibration is extrapolated. Aosai et al. ${ }^{34}$ investigated the size distribution of rare earth elements (REEs) in granitic groundwater samples collected from a different borehole at the same depth in the Mizunami URL as that of the present study, using an in situ micro/ultrafiltration device and scanning electron microscopy energy dispersive Xray spectroscopy (SEM-EDX). They found that more than $50 \%$ of REEs were associated with colloids with size ranges of $10 \mathrm{kDa}$ to $0.2 \mu \mathrm{m}$ and $0.2-0.45 \mu \mathrm{m}$, consisting of $\mathrm{Fe}, \mathrm{Al}, \mathrm{Mg}$, and $\mathrm{Si}$. Although the discrete nature of the filtration technique makes direct comparison difficult and $\mathrm{Si}$ and $\mathrm{Mg}$ were not successfully measured in this study, these findings seem to agree with the results in Fig. 2.

\subsection{Fl-FFF size distribution and composition of colloids in the sedimentary groundwater}

The size distribution of organic colloids and inorganic elements in the sedimentary groundwater are presented in Fig. 3. The gains for the UV/Vis and fluorescence detectors were 10 and 32 times more sensitive in the analysis of the granitic groundwater than those in the analyses of the sedimentary groundwater. Thus, colloids in the sedimentary groundwater are characterized by the high concentration of the organic colloids at $<5 \mathrm{~nm}$, reflecting the larger total organic carbon (TOC) in this groundwater (Table 1). The recovery rates of the organic colloids and the inorganic elements are shown in Table 3. Almost complete recovery of the organic colloids results both from the $\mathrm{UV} / \mathrm{Vis}$ and fluorescence fractograms, which contradict the corresponding values of the granitic groundwater. Although the reason for the large differences is unclear, they might indicate the different chemical nature of organic colloids in these deep groundwater samples, which would result in different interaction with the accumulation wall. Polyatomic interferences and/ or some contaminations were suspected for $\mathrm{Al}$ and $\mathrm{La}$, as discussed for the granitic groundwater. Both $\mathrm{Ca}$ and $\mathrm{Sr}$ showed similar and small recovery rates; the recover rates of Mo and W, which were less than $10 \%$ for the granitic groundwater, were more than $30 \%$ for the sedimentary groundwater.

All inorganic elements exhibit peaks in a similar size range as the organic colloids. This suggests an important role for organic colloids as host phases for the inorganic elements, as is the case for the granitic groundwater. Aluminum and Fe show additional peaks at $>5 \mathrm{~nm}$; Al has three peaks at $t_{\mathrm{r}}=6\left(d_{\mathrm{H}}=10\right.$ $\mathrm{nm}$ ), and 20, and $30 \mathrm{~min}$; Ca has a peak around $t_{\mathrm{r}}=30 \mathrm{~min} ; \mathrm{Fe}$ has a broad peak around $t_{\mathrm{r}}=20 \mathrm{~min}$. As no peaks are observed in the UV/Vis and fluorescence fractograms in these $t_{\mathrm{r}}$, the results indicate that inorganic colloids including these elements exist at relatively large sizes. Some of the elements such as $\mathrm{Cu}\left(t_{\mathrm{r}} \sim 20 \mathrm{~min}\right)$ and $\mathrm{Sr}\left(t_{\mathrm{r}}>30 \mathrm{~min}\right)$ have small peaks in these regions. As the concentrations of these elements in the fractograms are smaller than those of $\mathrm{Al}, \mathrm{Ca}$, and $\mathrm{Fe}$, they may bind to such inorganic colloids.

Kozai et al. ${ }^{22}$ measured the molar mass distribution of organic materials and various elements in sedimentary groundwater sampled at $-500 \mathrm{~m}$ of a surface well at the Horonobe URL by SEC-ICP-MS. They found multiple peaks of organic materials and inorganic elements in the $<150 \mathrm{kDa}$ 


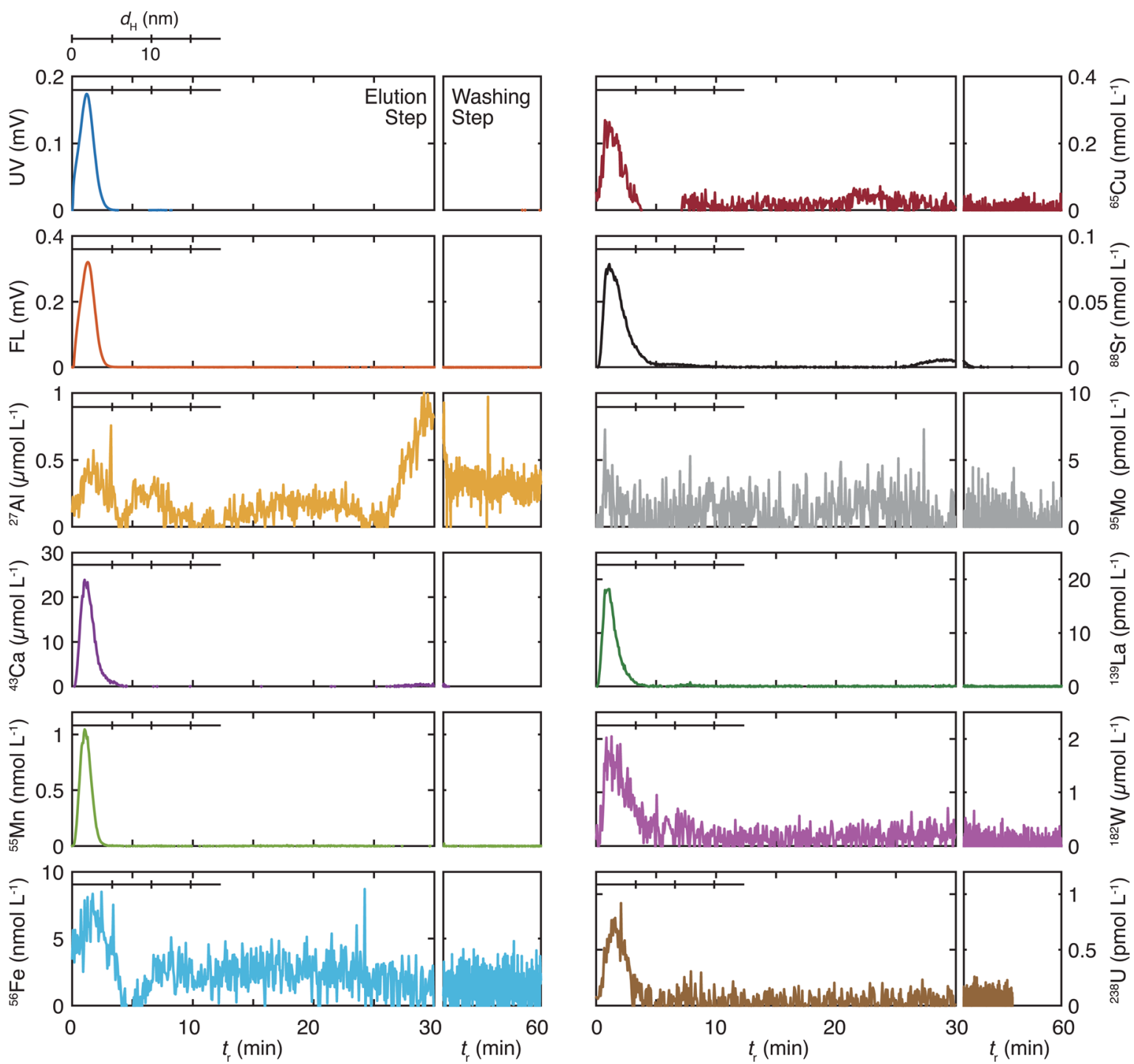

Fig. 3 Fl-FFF fractograms of the organic colloids and the inorganic elements in the sedimentary groundwater as a function of the retention time $\left(t_{r}\right)$. The range of $t_{r}$, which was calibrated for the hydrodynamic diameter $\left(0 \leq d_{H} \leq 18.7 \mathrm{~nm}\right)$, is given in each fractogram. The organic colloids were measured by the UV/Vis (UV) and fluorescence (FL) detectors. The elution profiles of colloids in the washing step are also presented as a function of $t_{\mathrm{r}}$.

region of the chromatograms, which may correspond to the size of 3-4 nm. They concluded that $U$ was associated with low molecular-weight Si species ( 1500 Da) containing $\mathrm{Na}, \mathrm{K}, \mathrm{Ca}$, and Al. Although the comparison of their SEC results and the FlFFF results in this study is not straightforward, as the fractionation range and resolution are rather different, it is most likely that the peaks at $<5 \mathrm{~nm}$ in Fig. 3 consist of various components.

\subsection{Comparison of the Fl-FFF results of the granitic and sedimentary groundwater}

The fractograms of organic colloids in the granitic and sedimentary groundwater are compared in Fig. 4. Organic colloids exist in similar size ranges in these groundwater samples; nevertheless their detailed distributions are different. In the granitic ground water the UV/Vis and fluorescence fractograms have peaks at 2.4 and $3.2 \mathrm{~nm}$, respectively, indicating the presence of organic colloids with different compositions of chromophores and fluorophores, depending on their sizes. Different size distributions were also obtained from UV/Vis and fluorescence detectors in the Fl-FFF analysis of marine dissolved organic materials. ${ }^{35}$ In contrast, organic colloids in the sedimentary groundwater likely consist of relatively homogeneous organic materials, as the peak positions of the UV/Vis and fluorescence fractograms coincide. It is also apparent that organic colloids in the sedimentary groundwater are more fluorescent than those in the granitic groundwater.

The fractograms of the selected inorganic elements are compared in the size range up to $10 \mathrm{~nm}$ in Fig. 5. Once normalized and overlaid, it is clear that the inorganic elements in the granitic groundwater exist in larger sizes than those in the sedimentary groundwater. In the granitic groundwater the 


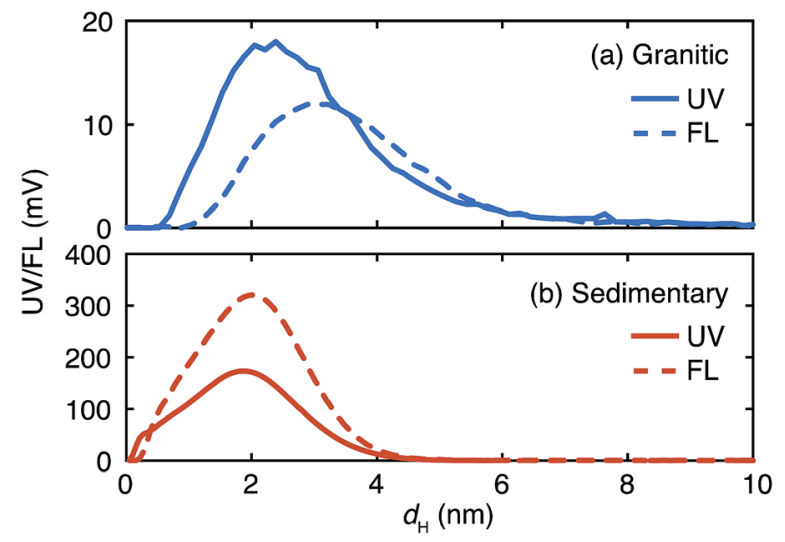

Fig. 4 Comparison of the UV/Vis (UV) and fluorescence (FL) fractograms of the organic colloids up to $10 \mathrm{~nm}$ in the granitic (a) and sedimentary (b) groundwater.

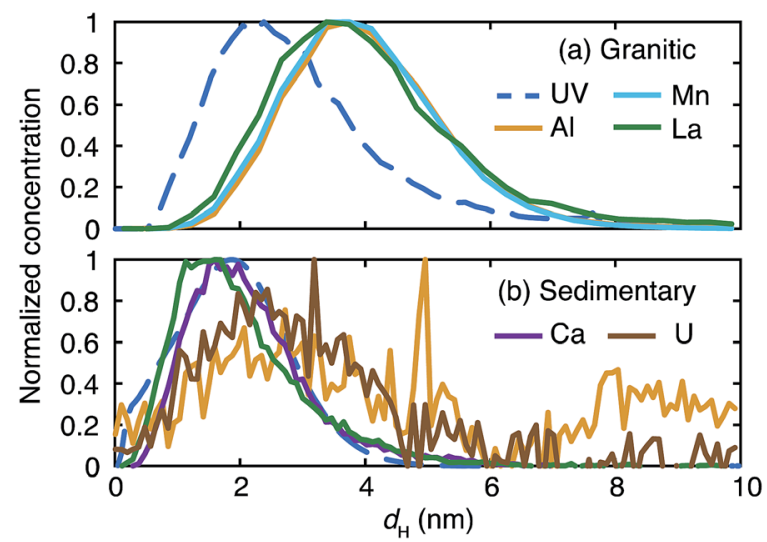

Fig. 5 Comparison of the normalized fractograms of the organic colloids measured by UV/Vis absorption and selected inorganic elements up to $10 \mathrm{~nm}$ in the granitic (a) and sedimentary (b) groundwater.

fractograms of the different elements tend to overlap with each other; the peak positions are around $4 \mathrm{~nm}$ and different from that of the corresponding UV/Vis fractogram, but close to that of the fluorescence fractogram (Fig. 4). This may indicate stronger binding of these elements to organic colloids rich in fluorophores. Another possibility is the presence of inorganic colloids composed of, for instance, $\mathrm{Al}$, whose concentration is relatively high in the Fl-FFF-ICP-MS analysis, and the uptake of trace elements such as $\mathrm{Mn}$ and $\mathrm{La}$, as mentioned above. The fractograms of the inorganic elements in the sedimentary groundwater depend on the types of elements and can be categorized into two groups. The elements in the first group are $\mathrm{Ca}, \mathrm{Mn}$, and La; they have relatively narrow peaks with maxima from 1.5 to $2 \mathrm{~nm}$, which correspond with those in the fractogram of the organic colloids. The second group may include $\mathrm{Al}$, $\mathrm{Fe}, \mathrm{Cu}, \mathrm{Sr}, \mathrm{W}$, and $\mathrm{U}$; they exhibit broader peaks with maxima around $2.5 \mathrm{~nm}$. Similar to the granitic groundwater there might be inorganic colloids in this size range, which capture trace elements such as $\mathrm{U}$.

\section{Conclusions}

The size distribution and elemental composition of colloids in different types of groundwater were examined over a wide range of sizes, using Fl-FFF coupled with ICP-MS. The gradient cross flow technique was used to extend the fractionation range, and elution of organic materials and inorganic elements in the washing step was monitored. Different concentration techniques were employed to deal with relatively low concentration of groundwater colloids.

In summary the fractograms of the organic colloids and those of most of the inorganic elements strongly overlapped at $<10 \mathrm{~nm}$ for both groundwater samples. At $>10 \mathrm{~nm}$ some inorganic elements ( $\mathrm{Al}, \mathrm{Ca}, \mathrm{Fe}, \mathrm{Cu}$, and $\mathrm{Sr}$ ) exhibited peaks in their fractograms, suggesting the presence of larger inorganic colloids. Organic colloids in the granitic groundwater were determined to be heterogeneous with respect to their sizes and the compositions of chromophores and fluorophores, in contrast to those in the sedimentary groundwater. Most of the inorganic elements at $<10 \mathrm{~nm}$ in the granitic groundwater showed peaks at similar sizes, corresponding to the peak location of the fluorescence fractogram of this groundwater. On the other hand, the distributions of the inorganic elements in this size range of the sedimentary groundwater were divided to two groups; one included $\mathrm{Ca}, \mathrm{Mn}$, and $\mathrm{La}$, having similar fractograms to the colloids; the other included $\mathrm{Al}, \mathrm{Fe}, \mathrm{Cu}, \mathrm{Sr}, \mathrm{W}$, and $\mathrm{U}$ and exhibited broader fractograms with maxima around 2.5 $\mathrm{nm}$. Complementary use of SEC, which has higher resolution in a smaller size region, would further resolve them..$^{22}$ Various offline microscopic techniques such as transmission electron microscopy and atomic force microscopy have been combined with Fl-FFF to further reveal the identities of size-fractionated colloids; ;0,36-38 such a combination should also work for Fl-FFF analyses of deep groundwater colloids. Locational and temporal variations of the size distributions and compositions of groundwater colloids should be investigated and discussed in relation to their correlation with corresponding geochemical and geological parameters.

\section{Acknowledgements}

The authors (T.S. and T.H.) thank Dr Hirota and Dr Munemoto for their assistance in the groundwater sampling at the Mizunami URL and Dr Murakami for his assistance in the groundwater sampling at the Horonobe URL. The authors also would like to thank valuable comments and suggestions from two anonymous reviewers. This research was partly supported by “Grant-in-Aid for Young Scientists (B)" (Grant no. 25820446), the Japan Society for the Promotion of Science.

\section{Notes and references}

1 M. Filella, in Environmental Colloids and Particles: Behaviour, Separation and Characterisation, ed. K. J. Wilkinson and J. R. Lead, Wiley, Chichester, 2007, pp. 17-94. 
2 B. L. Allen and B. F. Hajek, in Minerals in Soil Environments, ed. J. B. Dixon and S. B. Weed, Soil Science Society of America, Madison, 2nd edn, 1989, pp. 199-278.

3 E. Tipping, Cation binding by humic substances, Cambridge University Press, Cambridge, 2002.

4 J. D. Kubicki and S. E. Apitz, Org. Geochem., 1999, 30, 911927.

5 D. L. Sparks, Environmental Soil Chemistry, Academic Press, London, 2003.

6 L. K. Koopal, T. Saito, J. P. Pinheiro and W. H. van Riemsdijk, Colloids Surf., A, 2005, 265, 40-54.

7 J. F. Mccarthy and J. M. Zachara, Environ. Sci. Technol., 1989, 23, 496-502.

8 D. Grolimund, M. Borkovec, K. Barmettler and H. Sticher, Environ. Sci. Technol., 1996, 30, 3118-3123.

9 A. B. Kersting, D. W. Efurd, D. L. Finnegan, D. J. Rokop, D. K. Smith and J. L. Thompson, Nature, 1999, 397, 56-59.

10 A. P. Novikov, S. N. Kalmykov, S. Utsunomiya, R. C. Ewing, F. Horreard, A. Merkulov, S. B. Clark, V. V. Tkachev and B. F. Myasoedov, Science, 2006, 314, 638-641.

11 S. Kurosawa, S. C. James, M. Yui and M. Ibaraki, J. Colloid Interface Sci., 2006, 298, 467-475.

12 P. Vilks, H. G. Miller and D. C. Doern, Appl. Geochem., 1991, 6, 565-574.

13 C. Degueldre, R. Grauer, A. Laube, A. Oess and H. Silby, Appl. Geochem., 1996, 11, 697-710.

14 C. Degueldre, I. Triay, J. I. Kim, P. Vilks, M. Laaksoharju and N. Miekeley, Appl. Geochem., 2000, 15, 1043-1051.

15 M. W. Hahn, D. Abadzic and C. R. O'Melia, Environ. Sci. Technol., 2004, 38, 5915-5924.

16 O. Gustafsson and P. M. Gschwend, Limnol. Oceanogr., 1997, 42, 519-528.

17 J. R. Lead and K. J. Wilkinson, in Environmental Colloids and Particles: Behaviour, Separation and Characterisation, ed. K. J. Wilkinson and J. R. Lead, Wiley, Chichester, 2007, pp. 1-15.

18 B. Stolpe, Z. Z. Zhou, L. D. Guo and A. M. Shiller, Mar. Chem., 2014, 164, 25-37.

19 T. Saito, Y. Suzuki and T. Mizuno, Colloids Surf., A, 2013, 435, 48-55.

20 D. J. Lapworth, B. Stolpe, P. J. Williams, D. C. Gooddy and J. R. Lead, Environ. Sci. Technol., 2013, 47, 2554-2561.
21 M. Hassellov, B. Lyven, C. Haraldsson and W. Sirinawin, Anal. Chem., 1999, 71, 3497-3502.

22 N. Kozai, T. Ohnuki and T. Iwatsuki, Water Res., 2013, 47, 1570-1584.

23 B. B. M. Sadi, K. Wrobel, K. Wrobel, S. S. Kannamkumarath, J. R. Castillo and J. A. Caruso, J. Environ. Monit., 2002, 4, 1010-1016.

24 P. Schmitt-Kopplin and J. Junkers, J. Chromatogr. A, 2003, 998, 1-20.

25 M. A. Rodriguez and D. W. Armstrong, J. Chromatogr. B, 2004, 800, 7-25.

26 K. G. Wahlund and J. C. Giddings, Anal. Chem., 1987, 59, 1332-1339.

27 A. Hakansson, E. Magnusson, B. Bergenstahl and L. Nilsson, J. Chromatogr. A, 2012, 1253, 120-126.

28 E. Magnusson, A. Hakansson, J. Janiak, B. Bergenstahl and L. Nilsson, J. Chromatogr. A, 2012, 1253, 127-133.

29 K. Hama, T. Kunimaru, R. Metcalfe and J. Martin, Phys. Chem. Earth, 2007, 32, 170-180.

30 T. Iwatsuki, R. Furue, H. Mie, S. Ioka and T. Mizuno, Appl. Geochem., 2005, 20, 2283-2302.

31 M. Hassellöv, F. von der Kammer and R. Beckett, in Environmental Colloids and Particles. Behaviors, Separation and Characterisation, ed. K. J. Wilkinson and J. R. Lead, John Wiley \& Sons, Chichester, 2007.

32 Y. Zhang and B. G. Amsden, Macromolecules, 2006, 39, 10731078.

33 B. Stolpe, L. D. Guo, A. M. Shiller and M. Hassellov, Mar. Chem., 2010, 118, 119-128.

34 D. Aosai, Y. Yamamoto, T. Mizuno, T. Ishigami and H. Matsuyama, Colloids Surf., A, 2014, 461, 279-286.

35 M. Hassellov, Mar. Chem., 2005, 94, 111-123.

36 M. Baalousha and J. R. Lead, Environ. Sci. Technol., 2007, 41, 1111-1117.

37 M. Baalousha, F. V. D. Kammer, M. Motelica-Heino and P. Le Coustumer, J. Chromatogr. A, 2005, 1093, 156-166.

38 M. Baalousha, F. V. D. Kammer, M. Motelica-Heino, M. Baborowski, C. Hofmeister and P. Le Coustumer, Environ. Sci. Technol., 2006, 40, 2156-2162. 